\title{
Analysis of escalator tunnels deformations, when exposed to soils freezing
}

\author{
Diana Mukminova, ${ }^{1, *}$, and Evgeny Volohov ${ }^{1}$ \\ ${ }^{1}$ Saint-Petersburg Mining University, 199106, 2, 21st ling. V.O., St. Petersburg, Russia
}

\begin{abstract}
The presented work studies deformation processes of escalator tunnels support lining constructed by means of soils freezing in difficult engineering and geological conditions. The features of construction technology are considered. The features of the freezing effects during the active, passive stage of freezing and during the natural thawing of soils are considered. The data of the long-term arch support monitoring, as well as the earth's surface is presented. The non-standard nature of geomechanical processes, in particular the support lifting during the construction of the escalator tunnel is revealed. Methods of mathematical statistics and error theory were used to process and analyze data of field observations at surface and array displacements and deformations. According to survey observations on a few escalator tunnels in Saint-Petersburg underground the correlation form shown is increased in horizontal diameter of the rings and reduce the vertical dependence of the sedimentation casing from subsidence of the earth's surface. The data also reveals that with increasing development depth, despite the increase in vertical load, the deformation of the lining is reduced, which is associated with physical and mechanical properties of the array.
\end{abstract}

\section{Introduction}

In the construction of escalator tunnels, the sinking begins at the ground surface and ends at the depth of the underground station. Engineering and geological conditions of the upper (usually Quaternary) rock strata are estimated as extremely unfavorable, due to the presence of weak, unstable rocks and due to the presence of aquifers (sometimes several)[1]. To ensure the rocks stability during mining operations, exclude falls and collapses possibility, the elimination of significant water flows, as well as reduction rock mass deformation and the subsidence of the earth's surface, special methods are used. During the construction of escalator tunnels in such conditions, it is mainly envisaged to create a temporary ice-ground fence.

\footnotetext{
* Corresponding author: diana10.93@mail.ru
} 
When the excavation is carried out at a slope of 30 degrees, it crosses all layers of Quaternary sediments lying directly under the cultural layer. These deposits are usually unstable rocks, mainly sandy loams and loams, which prevents the use of conventional methods of sinking. Before the start of mining operations, the massif is secured around the mine by the creation of a temporary ice-ground fence using artificial freezing technology. The coolant circulates through the wells drilled around the future structure and an iceground ring is created around the design circuit of the development. This process is divided into two stages [2]:

1. Active, serving to create an ice-ground fence immediately preceding the beginning of tunneling, lasting about 2 months;

2. Passive, serving to maintain a negative temperature in the ice ring during the construction of an escalator tunnel in Quaternary sediments.

An important rational aspect of the protective measures mentioned above is the reliability of predictive displacements and deformations assessment. Here the situation looks safer, engineering forecasting methods are developed and used for the conditions of the escalator tunnels penetration by freezing. For example, in Saint-Petersburg to date, the impact assessment method described in the "Manual on the measures to protect operated buildings and structures from the mining operations influence in the construction of the subway" Podakov V.F. [3]. The forecasting method is focused on the application of typical curves method and is associated with the primary assessment of the main parameters for displacements muld: the maximum subsidence value, the maximum subsidence point position. The magnitude and position of maximum subsidence for the main longitudinal cross-section calculated according to the methodology proposed by Silvestrov S.N., Ovsyanko E.A. and V.F. Podatkov:

$$
\eta_{0}=\frac{\left[\delta_{p}^{2}+\delta_{p}\left(0,64 D_{v}+0,36 D_{h}\right)\right] l_{a v} \sqrt{m_{0} h}}{0,23 K_{p} L_{y}}
$$

where $\delta_{\mathrm{p}}$ - fence wall thickness, $\mathrm{m} ; \mathrm{D}_{\mathrm{v}}$ - the vertical diameter, $\mathrm{m} ; \mathrm{D}_{\mathrm{h}}$ is the horizontal diameter, $m ; l_{a v}$ - the weighted average value of the frozen thickness relative compaction; $h$ - power, m; Lu - length of the shear muld in the main section, $\mathrm{m} ; \mathrm{m}_{0}$ - parameter determining the slopes steepness, $1 / \mathrm{m} 2 ; \mathrm{Kr}$ - loosening coefficient (for watered soils take $\mathrm{Kr}=1.0$; for unwater soils $-\mathrm{Kr}=1.08$ ).

The maximum subsidence point position in the main section of the displacement muld, passing along the axis of escalator tunnel, is determined by the formula:

$$
\mathrm{D}=0,26 \mathrm{~L} \text {, }
$$

where L - length of an escalator tunnel.

As can be seen from the formula, the technique is replete with parameters and coefficients, the values of which should be determined by individual studies. These parameters are not given in the Manual [4]. They are largely dependent on geological conditions and time factor and are associated only with the stage of thawing.

However, these equations, according to the author, require further confirmation, for which it is necessary to lay special observation stations with soil reference points on the surface and deformation points in the arch and the lining tray. In addition, this dependence is poorly suited for the stage of thawing, when subsidence does not develop due to deformations of the support, but due to changes in the stress-strain state and transformation of the rocks properties after disabling freezing.

More and more information in modern works often devoted to the assessment of mining impact and construction works on the stress-strain state, where researchers rely on mathematical modeling by the finite element method. For example, in the works of Potemkin Da and Belyakov N. Ah. an attempt was made to estimate the displacements of rocks and the earth's surface by the results of such modeling. The authors concluded that the displacements on the earth's surface are directly related to the thickness of the ice 
barrier. Comparison of the data obtained in this simulation with the data on the method from "Manual..." [5] and by nature showed a significant difference. This is partly due to a significant freezing of the soil in excess of the design (calculated under the conditions of the ice barrier strength) volume, as well as the fact that the total value of subsidence consists of two component groups: due to freezing and rocks thawing and the actual mining operations during tunneling, which are difficult to take into account at the same time. This method is often taking place in practice. The main drawback of such model studies that should be recognized is not sufficient usage of data from the surveying measurements results, which in principle allows to verify such finite element models.

\section{Method}

\subsection{General information about construction technology}

The essence of the soils freezing method is that around the future construction of an artificial way to create a temporary ice-ground fence. First, wells are drilled by rotary machines using casing pipes, then freezing columns are placed in them, then collector and distribution pipes of the brine network are mounted (see Figure 1). After, brine freezing wells are equipped with freezing columns, which continuously circulates coolant. When passing through the freezing column, heat exchange process occurs between the column and the surrounding rocks (the brine is heated and the rocks are cooled). The brine circulates through the freezing columns in a closed loop and is cooled again at the freezing station. As a result, the water contained in the rocks gradually turns into ice. This leads to a significant change in their physical, mechanical and filtration properties: significantly increases the compressive and tensile strength, adhesion, multiplies the deformation modulus, dramatically reduces the filtration characteristics of water-saturated rocks [6].

During the soils freezing process, systematic observation of the ice-ground fence formation, its real size and temperature should be provided. The following indicators are determined during the observation:

1. the soils temperature in special thermometric wells (see wells Tc in Figure 2) to measure the temperature of the outer surface of the ice-ground fence;

2. the cooling brine temperature on the direct and reverse lines of the brine line;

3. control of the ice-ground fence closure and the groundwater level in hydro-observation wells.

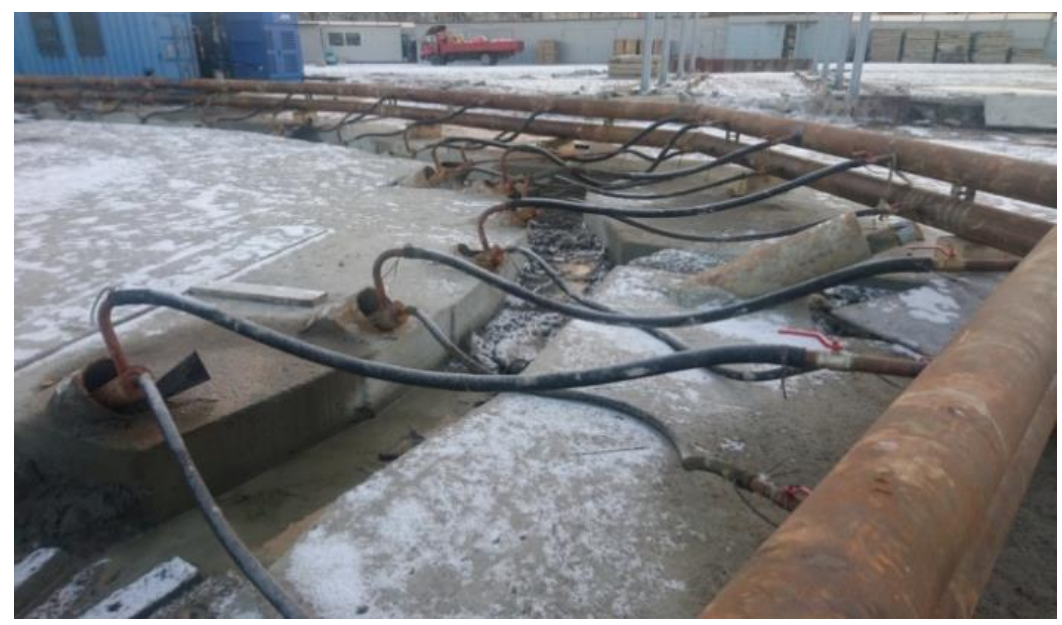

Fig. 1. Excavation of the escalator tunnel with the help of freezing method. 
The main purpose of such observations is to assess the ice barrier quality. The only calculated parameter in the traditional practice for data analysis of such observations is the ice barrier achieved thickness, which is compared with the calculated one for the project [7].

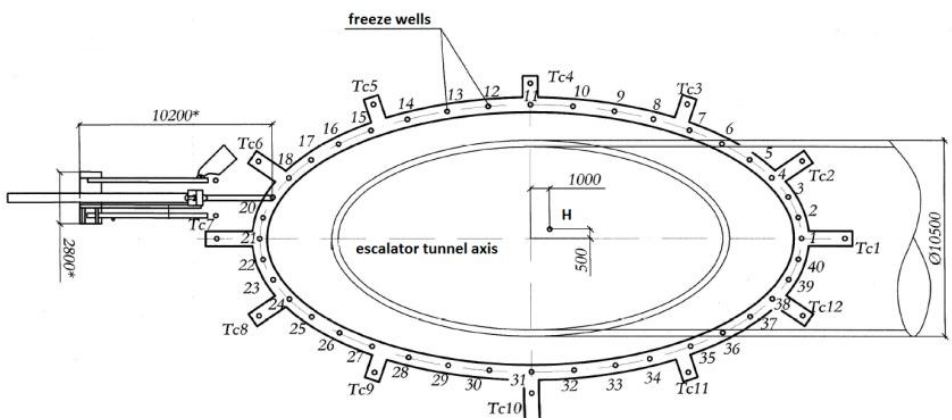

Fig.2. Location of freezing, thermometric and hydro-observation wells at the surface level of the construction site.

Mining operations during the escalator tunnels construction are carried out in watered conditions, so the rate of penetration is small (about $25 \mathrm{~m} / \mathrm{month}$ ). Development is carried out manually by means of jackhammers, installation (figure 3 ).

Tubes are delivered to the installation site on a special cart and grab the hands of the stacker are fed to the installation site. The Assembly of the ring is carried out sequentially: one element on both sides with the help of mounting tools and devices.

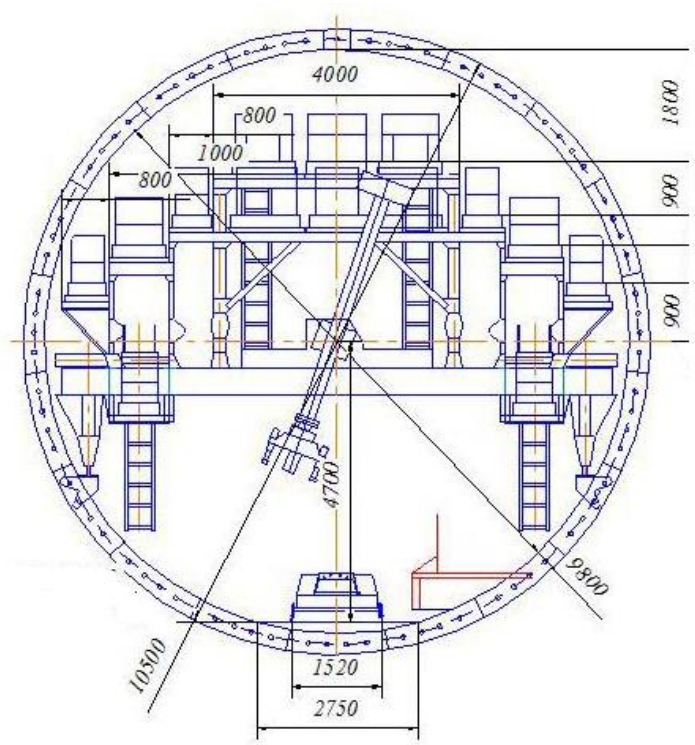

Fig.3. Escalator tunnel construction. Tube stacker TNU-4MA.

\subsection{Full-scale studies of rocks displacement and deformation processes}

The comprehensive study of the displacement and deformation processes, which manifest themselves during the construction of underground structures, requires an integrated approach. It involves creation of a coherent system for the surface monitoring, the massif, and the infrastructure utilities in the affected area. 
In Russia, monitoring of the Earth's surface in tunnel construction is regulated by the list of normative documents. According to [8], a monitoring station should consist of lines of reference points located across and along the axis of the tunnel.

During the escalator tunnels construction at Saint-Petersburg metro stations "Mezhdunarodnaya", "Prospekt Slavy II" that were open for passengers in 2012 and 2019, respectively, the profiles of the reference points were placed in the zones of important facilities undermining (buildings, highways, and railways). Observations were performed by JSC "Firm "GIRO" once in two weeks. The vertical and the horizontal components of displacement were recorded by geodetic methods. Due to the fact that the main goal of this monitoring was ensuring the undermined facilities safety, the profiles location of observation stations, the distance between the reference points, and the measurement frequency did not allow further use of this information for parameters studying of surface deformations development and distribution. The distance between the reference points in the profile line ranged from $20 \mathrm{~m}$ to $40 \mathrm{~m}$. Displacements had been monitored for two years. This rather long observations period gives an opportunity to detect changes in the nature of surface displacement after the object construction, to assess manifestation of creeping deformation.

Also, In the escalator tunnels construction at "Mezhdunarodnaya", "Prospekt Slavy II" and "Tekhnologicheskiy Institut II" stations, deformations observations of their lining were made. Measurements were made behind the vault, the tray and the horizontal diameter of the lining on each fifth ring.

At the moment, an observation station has been laid on the object under construction of "Kazakovskaya" metro station, surveying observations of the earth's surface movement, as well as the influence of freezing effects on the support are being conducted.

\section{Results}

\subsection{The monitoring results of the lining support movements}

During the construction of escalator tunnels with an outer diameter of $10.5 \mathrm{~m}$ at the "Mezhdunarodnaya" and "Prospekt Slavy II" metro stations in Saint-Petersburg, deformations observations of their lining were made. Measurements were made behind the vault, the tray and the horizontal diameter of the lining on each fifth ring. Studying the data on vertical subsidence, it can be determined that the maximum deformation occurs when the layers production of aquifer sandy loams lying close to the earth's surface, the subsidence of the arch reaches $150 \mathrm{~mm}$. With increasing depth, the vertical load increases, but the deformation of the lining decreases, subsidence reaches $20 \mathrm{~mm}$. this is due to changes in hydrogeological parameters and physical and mechanical properties of the array.

Studying the data on the vertical diameter reduction of the the inclined stroke lining, it was revealed that the vertical deformations are proportional to the increase in the horizontal diameters of the rings. Statistical processing of the observations of the first 40 rings gave a relationship between the decrease in the vertical diameter and the increase in the horizontal for the escalator tunnel "Technologicheskiy Institut II" with a diameter of $8.5 \mathrm{~m}$, obtained in the studies of Dolgikh M.V.:

correlation coefficient $\mathrm{r}=0,967$

$$
\Delta D_{h}=1,127 \Delta D_{v}+14,4
$$


Table 1. Dependence between deformations of vertical and horizontal lining diameters $\varnothing 8.5 \mathrm{~m}$ for escalator tunnel "Technologicheskiy Institut II"

\begin{tabular}{|c|c|c|c|c|c|c|c|c|c|}
\hline Number & $\mathbf{1}$ & $\mathbf{5}$ & $\mathbf{1 0}$ & $\mathbf{1 5}$ & $\mathbf{2 0}$ & $\mathbf{2 5}$ & $\mathbf{3 0}$ & $\mathbf{3 5}$ & $\mathbf{4 0}$ \\
\hline$\Delta \mathrm{Dh}, \mathrm{mm}$ & +50 & +125 & +230 & +243 & +110 & +105 & +100 & +100 & +20 \\
\hline actual. $\Delta \mathrm{Dv}, \mathrm{mm}$ & -52 & -148 & -282 & -269 & -173 & -165 & -102 & -125 & -34 \\
\hline calculated. $\Delta \mathrm{Dv}, \mathrm{mm}$ & -60 & -150 & -276 & -292 & -132 & -126 & -120 & -120 & -24 \\
\hline
\end{tabular}

Statistical data processing of the first 50 rings for escalator tunnels with a $10.5 \mathrm{~m}$ diameter at "Prospect Slavy II" and "Mezhdunarodnaya" revealed the dependence of the decrease in the vertical diameter of the increase in the horizontal:

correlation coefficient $\mathrm{r}=0,967$

$$
\Delta D_{h}=1,139 \Delta D_{v}+15,1
$$

Table 2. Dependence between deformations of vertical and horizontal lining diameters $\varnothing 10.5 \mathrm{~m}$ for escalator tunnel "Mezhdunarodnaya" and "Prospekt slavy II "

\begin{tabular}{|c|c|c|c|c|c|c|c|c|c|c|c|}
\hline Number & $\mathbf{1}$ & $\mathbf{5}$ & $\mathbf{1 0}$ & $\mathbf{1 5}$ & $\mathbf{2 0}$ & $\mathbf{2 5}$ & $\mathbf{3 0}$ & $\mathbf{3 5}$ & $\mathbf{4 0}$ & $\mathbf{4 5}$ & $\mathbf{5 0}$ \\
\hline$\Delta \mathrm{Dh}, \mathrm{mm}$ & +45 & +80 & +90 & +120 & +180 & +150 & +120 & +90 & +70 & +50 & +30 \\
\hline $\begin{array}{c}\text { actual. } \\
\Delta \text { Dv, } \mathrm{mm}\end{array}$ & -50 & -115 & -100 & -152 & -230 & -170 & -164 & -110 & -100 & -72 & -34 \\
\hline $\begin{array}{c}\text { calculated. } \\
\Delta \text { Dv, } \mathrm{mm}\end{array}$ & -58 & -104 & -117 & -156 & -234 & -195 & -156 & -117 & -91 & -65 & -39 \\
\hline
\end{tabular}

In this case, the vertical deformation of the lining also decreases with increasing depth, despite the increase in the vertical pressure of the overlying rocks. Thus, it can be concluded that the maximum deformation of the inclined course lining will be observed in the area of its mouth at the intersection of extremely unstable water-saturated sandy loams. For a more detailed study of this question it is necessary not only to lay observation station represented by a chain of ground reference points, but simultaneously with measurements on the earth's surface to measure deformations of the lining with the vertical position definition of its arch and the tray and the change in horizontal diameter for the entire period of construction.

Observations of escalator tunnels subsidence at metro stations are made after their continuous commissioning for an average of 4 years since the shutdown of the artificial freezing system.

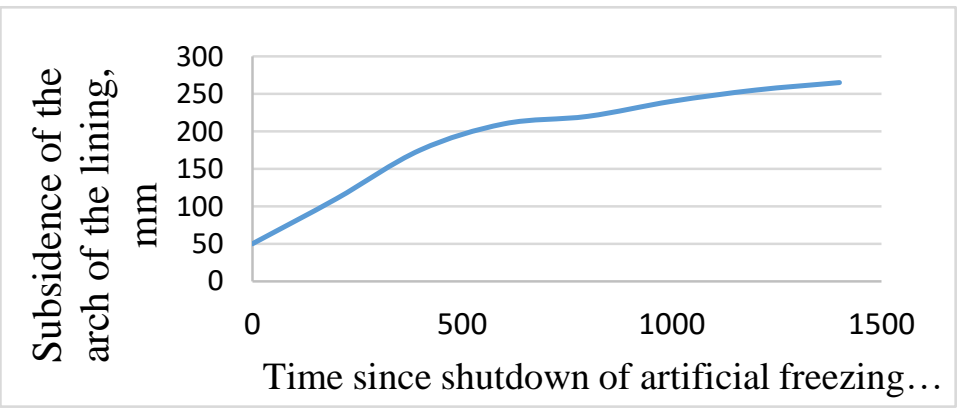

Fig. 4. Subsidence of the lining arch at "Prospekt slavy II" metro station. 
As the measurement data demonstrates, the deformation of the linings occur for a long time, but have a damping character (see figure 4), as well as subsidence on the earth's surface.

The subsidence of the arch is associated not only with a decrease in the vertical diameter, but also with a change in the spatial position of the entire development. Subsidence of escalator steps in the upper part of the inclined course in a year from the moment of installation reach $50-60 \mathrm{~mm}$.

\subsection{The result of long-term displacements and deformations monitoring of the Earth's surface}

To observe the buildings subsidence in the area of inclined passages of "Prospekt slavy II" station (see figure 5), wall reference points were laid, also lampposts were used as reference points. In this scheme the Supervisory station is not systemic, since the measurements objective is to control only the buildings condition and to study the escalator tunnel construction influence to the earth's surface is not possible [9].

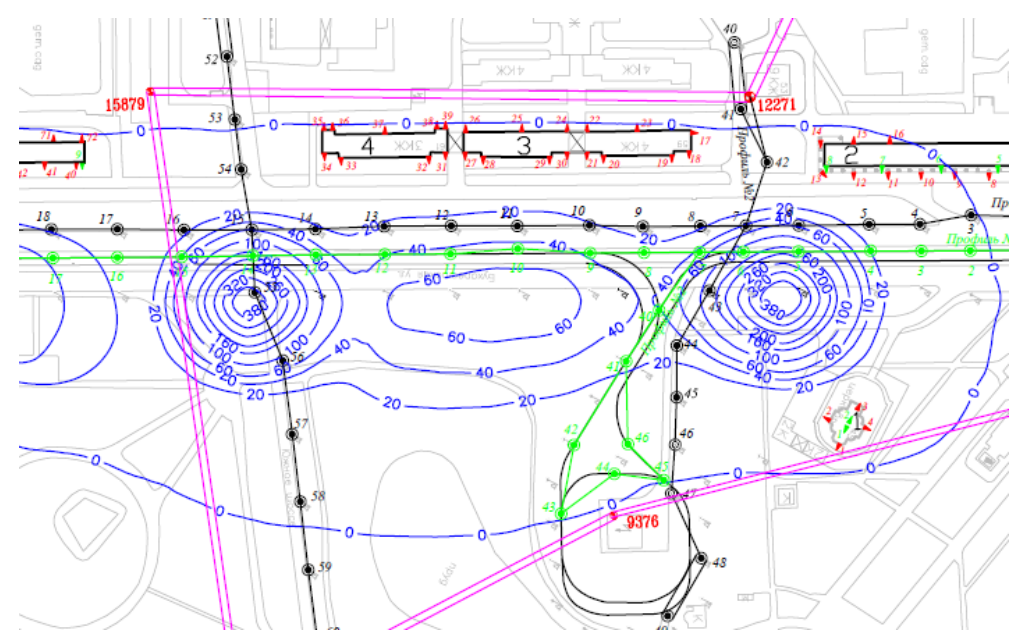

Fig.5. Diagram of the observation station for escalator tunnels of "Prospekt Slavy II" metro station.

As the ice-ground fence thaws, deformation of the lining occurs and, as a consequence, further subsidence of the earth's surface (see figure 6) with the formation of the displacement muld limited by the angle of influence $\theta$ (from 300 to $450 \mathrm{~mm}$ ). However, it should be noted that the maximum values of the earth's surface subsidence (reach $450 \mathrm{~mm}$ ) significantly exceed the subsidence of the lining arches (reach $150 \mathrm{~mm}$ ). This is due to the compaction of rocks after thawing due to changes in the hydrogeological situation. When freezing, the transition of water into ice occurs with an increase in volume up to $10 \%$, which leads to the decompression of individual layers that have fallen into the contour of the ice-ground fence. After the end of mining operations, thawing of frozen rocks occurs with their compaction, and the tray part of the ice ring affects the position of the lining of the inclined course, and the upper half of the ring-on the subsidence of the earth's surface.

At processing of full-scale data of escalator tunnels "Prospekt slavy II" and "Mezhdunarodnaya" it is possible to assume:

$$
\begin{gathered}
\eta_{\mathrm{m}}=2,4 \Delta Z, \\
\text { here } \Delta Z=\Delta Z_{m}\left(0.317 \lg \frac{t}{t_{0}}\right)^{3}
\end{gathered}
$$




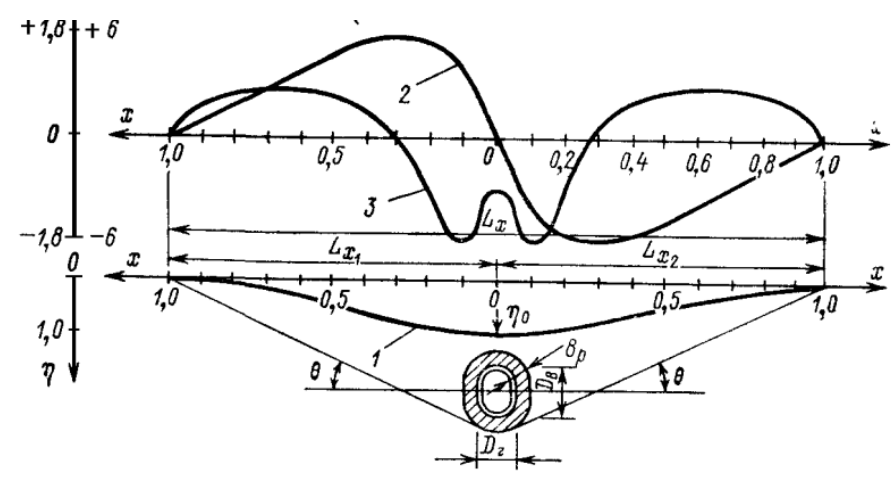

Fig.6. Subsidence of the earth's surface over the escalator tunnel.

where $\eta_{m}$ - subsidence on the earth's surface, $\Delta Z$ - the average subsidence of the arch lining, as a function of time $\mathrm{t}$ (time since the installation of the lining), $\Delta \mathrm{Z}_{\mathrm{m}}$ - the expected total subsidence of the arch, $\mathrm{t}_{0}=1$ day

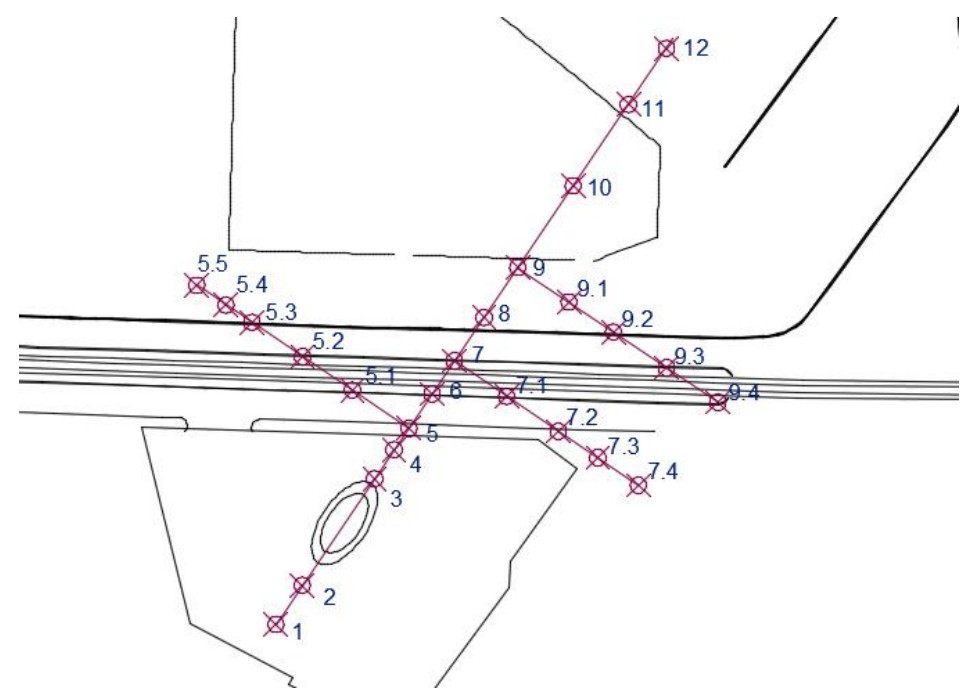

Fig.7. Observation station of the escalator tunnel of Kazakovskaya metro station.

When processing full-scale data of escalator tunnels "Prospekt Slavy II" and "Mezhdunarodnaya" it is possible to assume: this statement requires further confirmation, the construction of the inclined course oat the "Kazakovskaya" metro station of SaintPetersburg metro laid observation station (see figure 7), it is also planned to monitor the deformation of the lining.

\section{Discussion}

Studies of the linings deformations and full-scale data on the earth's surface have shown the need to observe the lining of the escalator tunnel not only of horizontal and vertical diameter. It is necessary to make observations of the "oblique" tubing, which will allow the most detailed study of the soil freezing effect on the support Also, when organizing fullscale observations, it is necessary to observe not only the buildings and structures being worked on, but also it is necessary to introduce additional profile lines across the stretch of the tunnel axis (at least in the zone of maximum subsidence and in the zone of maximum 
muld width). Prolongation of typical periods during periodic observations at the stage of subsidence damping (during thawing of the massif).

The following conclusions can be made:

1. the greatest deformation of the escalator tunnel lining is experienced in the area of crossing the aquifer sandy loam, while the relationship between the change in the vertical and horizontal diameters is revealed.

2. thawing of the ice-ground massif causes significant horizontal deformation of the earth's surface, so buildings and structures caught in the slide require structural protection measures.

3. the process of displacement during the sinking of inclined passages is insufficiently studied and requires a more systematic study. It is necessary to lay observation stations on a number of objects, represented by a chain of ground benchmarks stretched along the axis of the development with the simultaneous laying of two or more diameters. At the same time, observations should be made for the movement of reference points in horizontal and vertical directions. Simultaneously with measurements on the earth's surface, measurements of the deformation of the lining should be made with the determination of the arch and tray height position and the change in the horizontal diameter.

\section{Conclusions}

The existing methods of predicting displacements and deformations may be conditionally divided into three large groups: empirical and semi-empirical, analytical and analyticalempirical, mathematical modeling based on numerical methods. Of all these, only the numerical methods are capable of considering the features of active influence on the stress-strain state of the rock mass, including wide variation of excavation parameters. At the same time, direct use of numerical methods, such as the finite element method, without reliance on the field data, does not provide the results close to the reality. Verification of the same finite element models requires comprehensive information about the processes of the massif and surface deformation at analogous facilities.

The article presents and analyzes the data of monitoring the surface and lining of escalator tunnels, which will be used for further calculation of displacements and deformations in these mining and geological conditions. At the same time, we cannot say that the process of massif deformation has been completely studied even in this particular case. According to the results of monitoring, there are no data about changes in the size of the semi-pothole during the construction with the use of various excavation modes. The majority of the ground reference points were located above the axis of the tunnel. The nature of deformations distribution in the massif has not been completely studied. Wells with extensometers were located only above the axis of the tunnel in the locations of the maximum deformations. However, a significant contribution into the final distribution of displacements is also made by horizontal deformations at the level of the medial diameter in sides of the excavation.

To summarize, it is worth noting that, despite the significant amount of field data and the performed studies, the problem of assessing displacements and deformation with the use of the technologies with active influence on the massif is still relevant. To study the features of rock and Earth's surface deformation in such conditions, it is necessary to organize experimental plots, where the effect of changes in the complex subsystems operation will be studied, such as the earth pressure balance and injection systems. 


\section{References}

1. D.Z. Mukminova, S.Yu. Novozhenin, Min. Surv. Bull. №6 (2015)

2. G.V. Rudianov, E.I. Krapivsky, S.M. Danileiv, J. Mini. Ins. 231, 245- 253

3. E. M. Volokhov, Min. Surv. Bull., 5, 38-42 (2015)

4. E. M. Volokhov, Min. Surv. Bull., 3, 27-30 (2015)

5. K. P. Bezrodny, S. G. Gendler, Y. S. Isayev, URAN IPKON RAS, R\&D Design \& Survey Institute "Lenmetrogiprotrans" (2009)

6. F. Yang. Tunne, Sprin. Sci. Busi., 137-143 (2009)

7. M. Monjezi, B. N. Rahmani, S. R. Torab, ARCH. MIN. SCI., 57(3), 535-545 (2012)

8. E. F. Chumakov, A. N. Vyalykh, M. S. Pankratov, Sub. Tunn., 1, 8-10 (2013)

9. S. V. Mazein : Author's diss. ... d-r of tech. sciences (2013) 